\section{Finger to Nose Test}

Grant L. Iverson

Department of Psychiatry, University of British

Columbia British Columbia Mental Health \&

Addictions, Vancouver, BC, Canada is evidenced by difficulty in controlling the range of movement. Dysmetria can result in undershooting or overshooting the target stimuli (i.e., examiner's finger and/or examinee's nose). Damage to the cerebellum can adversely affect a person's ability to perform this test adequately.

\section{Cross-References}

The finger-to-nose-test measures smooth, coordinated upper-extremity movement by having the examinee touch the tip of his or her nose with his or her index finger. On one variation of the test, the examiner holds out his or her finger, about an arm's length from the patient. The patient is instructed to touch the examiner's finger and then his or her own nose. After several successful trials, the patient is then asked to repeat the action more quickly. Moving the target finger can increase the difficulty of the task.

\section{Current Knowledge}

This test is part of a comprehensive neurological examination. It is typically employed as part of coordination testing. The examiner looks for evidence of intention tremor or dysmetria. Dysmetria
- Cerebellum

- Tremor

\section{References and Readings}

Dietrichs, E. (2008). Clinical manifestation of focal cerebellar disease as related to the organization of neural pathways. Acta Neurologica Scandinavica, 188 (Suppl), 6-11.

Notermans, N. C., van Dijk, G. W., van der Graaf, Y., van Gijn, J., \& Wokke, J. H. (1994). Measuring ataxia: Quantification based on the standard neurological examination. Journal of Neurology, Neurosurgery, and Psychiatry, 57, 22-26.

Swaine, B. R., Desrosiers, J., Bourbonnais, D., \& Larochelle, J. L. (2005). Norms for 15- to 34-yearolds for different versions of the finger-to-nose test. Archives of Physical Medicine and Rehabilitation, 86, 1665-1669. 